\title{
Pengembangan Cerita Bergambar Bahasa Jawa (Cergam Baja) Untuk Siswa Sekolah Dasar
}

\author{
Ulfa Miftakhul Mufidah ${ }^{1}$, Sripit Widiastuti ${ }^{2}$, Desy Dwi Riana ${ }^{3}$ \\ ${ }^{1,2,3}$ Program Studi Pendidikan Guru Sekolah Dasar, Universitas Islam Balitar, Indonesia \\ Email: ${ }^{1}$ ulfamufidah025@gmail.com,2 phywidia@gmail.com, ${ }^{3}$ rianadesy12@gmail.com
}

\begin{abstract}
Abstrak
Pembelajaran bahasa Jawa di sekolah mempunyai peranan sangat penting dalam membentuk sikap dan pribadi siswa, karena dalam belajar bahasa Jawa siswa mengerti bagaimana menggunakan unggah-ungguh bahasa yang baik dan benar kepada orang yang lebih tua. Berdasarkan analisis kebutuhan dan wawancara menunjukkan bahwa dalam pembelajaran bahasa Jawa siswa kurang memahami cerita Jawa, siswa kurang memahami isi cerita karena penggunaan bahasa dalam cerita tersebut adalah bahasa standar. Kebanyakan sekolah juga hanya menggunakan buku Tantri Basa, bukan buku yang dapat menarik perhatian siswa. Penelitian ini bertujuan untuk menghasilkan produk buku bergambar bahasa Jawa (Cergam Baja) yang sesuai untuk pembelajaran bahasa Jawa. Jenis penelitian yang digunakan adalah $\mathrm{RnD}$ yang dikembangkan oleh Sugiyono dengan tujuh tahap. Instrumen yang digunakan dalam penelitian ini adalah angket, hasil validator kelayakan ahli cerita sebesar $86 \%$, ahli bahasa $89,3 \%$, dan ahli materi ajar 88,3\%. Hasil angket keterbacaan guru buku bergambar bahasa Jawa (Cergam Baja) diperoleh persentase 95,5\% dan hasil angket keterbacaan siswa diperoleh persentase 96\%. Berdasarkan hasil secara keseluruhan dapat disimpulkan bahwa buku Cergam Baja layak untuk digunakan sebagai bahan ajar.
\end{abstract}

Kata kunci: buku cerita bergambar, cerita bahasa jawa, perkembangan

\section{THE DEVELOPMENT OF DRAWIED STORIES IN JAVA (CERGAM BAJA) FOR PRIMARY SCHOOL STUDENTS}

\begin{abstract}
Learning Javanese in schools has a very important role in shaping students' attitudes and personalities, because in learning Javanese students understand how to use good and correct language uploads for older people. Based on the needs analysis and interviews, it shows that in learning Javanese students do not understand Javanese stories, students do not understand the contents of the stories because the use of language in the stories is standard language. Most schools also only use Tantri Basa books, not books that can attract students' attention. This study aims to produce a picture book product in Javanese language (Cergam Baja) which is suitable for learning Javanese. The type of research used was RnD developed by Sugiyono with seven stages. The instrument used in this study was a questionnaire, the results of the eligibility validator for storytelling experts were $86 \%$, linguists were $89.3 \%$, and teaching material experts were $88.3 \%$. The results of the questionnaire readability of the Javanese picture book teacher (Cergam Baja) obtained a percentage of $95.5 \%$ and the results of the student readability questionnaire obtained a percentage of $96 \%$. Based on the overall results, it can be concluded that the Cergam Baja book is suitable for use as teaching material.
\end{abstract}

Keywords: development, javanese language stories, picture story books

\section{PENDAHULUAN}

Bahasa merupakan bagian penting dari proses suatu komunikasi. Adanya bahasa memungkinkan antara dua individu atau lebih mengekspresikan berbagai ide, arti dan perasaan yang dialami. Bahasa memiliki fungsi sebagai alat komunikasi, alat untuk mengekspresikan diri dan alat untuk bersosialisasi dengan orang lain. Salah satu bahasa yang sering digunakan adalah bahasa Jawa. Bahasa yang merupakan warisan nenek moyang yang tak ternilai harganya. Menurut [1] bahasa Jawa adalah suatu bahasa daerah yang merupakan kebudayan nasional Indonesia, yang hidup dan tetap dipergunakan dalam masyarakat yang bersangkutan. Bahasa Jawa merupakan bahasa daerah yang perlu dilestarikan agar tidak hilang keberadaannya. Menurut [2] Bahasa Jawa merupakan salah satu bahasa daerah yang digunakan sebagai sarana komunikasi dalam kehidupan sehari-hari antara seseorang dengan orang lain oleh masyarakat Jawa. 
Bahasa tidak hanya digunakan dalam komunikasi orang dewasa saja, tetapi juga anak-anak. Sebagai proses penting dari komunikasi, maka bahasa yang merupakan warisan ini harus diperkenalkan sejak dini.

Pembelajaran bahasa Jawa di sekolah mempunyai peranan sangat penting dalam membentuk sikap dan pribadi siswa, karena dalam belajar bahasa Jawa siswa mengerti bagaimana menggunakan unggah-ungguh bahasa yang baik dan benar kepada orang yang lebih tua. Belajar berbahasa Jawa juga dapat menjadikan siswa mengerti tentang sopan santun dan bertutur kata yang halus. Pembelajaran bahasa Jawa wajib diajarkan untuk siswa sekolah dasar, sekolah menengah pertama dan sekolah menengah atas atau sederajat. Hal ini disampaikan oleh peraturan Gubernur Jawa Timur nomor 19 tahun 2014 bahwasanya mata pelajaran bahasa Jawa sebagai muatan lokal wajib di sekolah ataupun madrasah.

Menurut [3] tujuan mata pelajaran bahasa Jawa yaitu mengenal dan menjadi lebih akrab dengan lingkungan alam, sosial, dan budayanya, memiliki bekal kemampuan dan keterampilan serta pengetahuan mengenai daerahnya yang berguna bagi dirinya maupun bagi masyarakat umum, serta memiliki sikap dan perilaku yang selaras dengan nilai-nilai atau aturan-aturan yang berlaku di daerahnya serta melestarikan dan mengembangkan nilai-nilai luhur budaya setempat dalam rangka menunjang pembangunan nasional.

Materi dalam pembelajaran bahasa Jawa salah satunya adalah materi tentang cerita bahasa Jawa. Cerita bahasa Jawa yang diajarkan meliputi mengenal, memahami dan mengidentifikasi teks dalam cerita. Siswa perlu belajar memahami sebuah cerita bahasa Jawa karena dengan memahami siswa dapat mengetahui apa yang ingin disampaikan oleh penulis.

Pengembangan buku cerita bergambar berbahasa Jawa sebagai bahan ajar Bahasa Jawa oleh peneliti terdahulu diantaranya adalah seperti penelitian yang pernah dilakukan oleh [4] pada tahun 2017 menghasilkan produk berupa buku cerita bergambar berbahasa Jawa, respon siswa terhadap buku cerita bergambar yang dikembangkan adalah kebanyakan mereka antusias dalam mengikuti pembelajaran dan mereka mampu menjawab soal-soal yang ada dibuku cerita bergambar tersebut. Ada juga penelitian oleh [5] pada tahun 2016 menghasilkan produk berupa buku cerita sebagai upaya peningkatan penguasaan kosakata jawa siswa, respon siswa terhadap buku cerita tersebut menunjukkan respon yang positif, kondisi kelas tenang dan siswa fokus mendengarkan dongeng yang ada pada buku cerita yang dibacakan oleh guru. Berikutnya penelitian oleh [6] pada tahun 2013 menghasil produk berupa buku pengayaan cerita anak berbahasa Jawa, respon siswa terhadap buku tersebut menunjukkan respon yang baik, mereka antusias dalam pembelajaran.

Dari penelitian terdahulu terdapat beberapa kekurangan yaitu tidak adanya evaluasi dan refleksi, penggunaaan bahasa yang hanya ngoko saja, dan warna yang digunakan kurang menarik. Berdasarkan hal tersebut maka peneliti akan mengembangkan buku cerita bergambar berbahasa Jawa, pada buku ini berisi cerita yang memuat Pendidikan karakter, soal untuk evaluasi, refleksi berupa TTS, dan layout yang berwarna dan menarik. Maka peneliti melakukan penelitian pengembangan dengan judul "Pengembangan Buku Cerita Bergambar Bahasa Jawa (Cergam Baja) untuk siswa Sekolah Dasar”.

\section{METODE PENELITIAN}

Dalam penilitian ini menggunakan R\&D karena dari hasil analisis pengumpulan data awal dibutuhkan sebuah bahan ajar untuk meningkatkan pemahaman siswa terhadap cerita bahasa Jawa.

Prosedur penelitian yang digunakan dalam penelitian R\&D ini adalah model Borg and Gall yang telah diadopsi dan dikembangkan oleh Sugiyono. Adapun tahapan dalam pengembangan Borg and Gall yang telah dikembangkan oleh Sugiyono adalah (1) mencari potensi dan masalah, (2) melakukan penelitian dan pengumpulan data, (3) desain produk, (4) Validasi desain, (5) revisi desain, (6) melakukan uji coba produk, (7) revisi produk, (8) melakukan uji coba pemakaian, (9) revisi Produk final, (10) diseminasi dan implementasi. Rincian dari tahapannya dalah sebagai berikut.

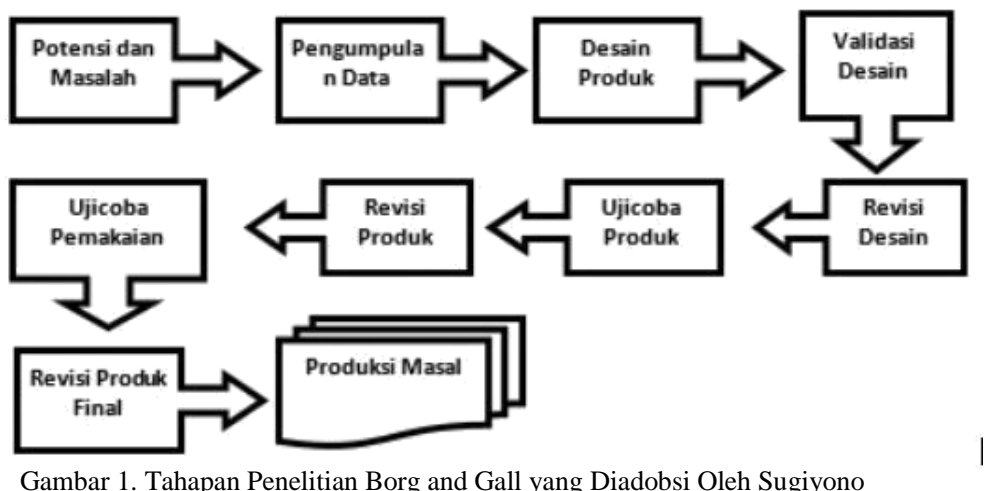


Penelitian ini awal dilaksanakan di 3 sekolah dasar di Kota Blitar, yaitu UPT SD Negeri Sentul 1, UPT SD Negeri Sentul 3 dan UPT SD Negeri Kepanjen Lor 2. Waktu penelitian akan dilakukan pada tanggal 18, 19 dan 21 November 2019. Untuk uji coba produk dilaksanakan 2 sekolah, yaitu UPT SDN Mandesan 02 dan MI AlHuda Kebonrejo. Subjek penelitian ini yaitu 5 siswa kelas IV terdiri dari 2 laki-laki dan 3 perempuan yang berasal dari 2 sekolah yaitu UPT SDN Mandesan 02 dan MI Al- Huda Kebonrejo dan 5 guru terdiri dari 5 guru perempuan. Dalam penelitian ini menggunakan teknik sampel jenuh. Disini peneliti mengambil teknik sampling tersebut karena jumlah dari populasi sedikit, maka seluruh populasi dijadikan sebagai sampel.

Pengukuran kualitas buku Cergam Baja dilakukan dengan uji validasi dan uji keterbacaan. Uji validasi dilakukan kepada validator cerita, bahasa dan bahan ajar. Uji validasi dilakukan menggunakan angket validasi cerita, bahasa dan bahan ajar. Selanjutnya, dilakukan uji keterbacaan. Uji keterbacaan dilakukan dengan cara memberikan angket keterbacaan kepada siswa dan guru untuk penilaian siswa dan guru terhadap bahan ajar tersebut. Tahap penilaian tidak dilakukan sampai uji kelompok besar atau uji efektivitas karena keterbatasan waktu dan terkendala Covid 19.

Kriteria penghitungan untuk uji validasi dan uji keterbacaan guru menggunakan Skala Likert yaitu dengan menetapkan skor 5 sebagai tingkat ketercapaian maksimal kriteria yang dinilai dan skor 1 sebagai tingkat ketercapaian minimal kriteria yang dinilai. Sedangkan untuk uji keterbacaan siswa menggunakan Skala Guttman dengan menetapkan kata "Iya" bernilai positif dan kata "Tidak" bernilai negatif.

Penghitungan data uji validasi dan uji keterbacaan dilakukan dengan cara (1) melakukan rekapitulasi data penilaian dari validator dan subjek uji keterbacaan, (2) menentukan rata-rata nilai, (3) mengubah nilai dalam bentuk persentase, dan (4) persentase yang diperoleh dibandingkan dengan kriteria kelayakan bahan ajar. Kriteria kelayakan terdapat pada tabel 1 dan 2 sebagai berikut.

\begin{tabular}{|c|c|c|}
\hline $\begin{array}{l}\text { Tingkat } \\
\text { Pencapaian }\end{array}$ & $\begin{array}{l}\text { Tingkat } \\
\text { Kevalidan }\end{array}$ & Keterangan \\
\hline $90 \%-100 \%$ & Sangat layak & Tidak perlu revisi \\
\hline $75 \%-89 \%$ & Layak & Tidak perlu revisi \\
\hline $65 \%-74 \%$ & Cukup layak & Perlu revisi \\
\hline $55 \%-64 \%$ & Kurang layak & Perlu revisi \\
\hline $0 \%-54 \%$ & Tidak layak & Revisi total \\
\hline
\end{tabular}

\begin{tabular}{llll}
\multicolumn{3}{c}{ Tabel 2 . Indikator Penilaian Angket Keterbacaan Siswa } \\
\hline No & Kriteria & Positif & Negatif \\
\hline 1. & Iya & 1 & 0 \\
2. & Tidak & 0 & 1 \\
\hline
\end{tabular}

\section{HASIL DAN PEMBAHASAN}

\subsection{Uji Validasi}

Produk yang sudah jadi selanjutnya divalidasi kepada validator yang terbagi atas validator ahli cerita, validator ahli bahasa, dan validator ahli bahan ajar.

1) Validator Ahli Cerita

Validator cerita yang dipilih dalam penelitian ini adalah ahli cerita anak, dosen dan dari guru, karena validasi dilakukan untuk memastikan bahwa cerita yang ditulis telah memenuhi kriteria cerita anak yang baik dan agar mengetahui kriteria cerita yang biasanya diberikan kepada siswa SD. Persentase hasil uji validasi oleh ahli cerita terhadap buku Cergam Baja adalah $86 \%$. Berdasarkan persentase tersebut maka buku Cergam Baja termasuk dalam kategori layak untuk digunakan sebagai bahan ajar. Hal tersebut sesuai dengan ciri-ciri cerita anak yang dijabarkan oleh [7] bahwa ciri-ciri cerita anak dapat ditinjau dari beberapa segi yaitu (1) bentuk penyajian sesuai dengan dunia siswa, (2) bahasa yang digunakan sederhana, (3) cara penuturan yang sesuai dengan perkembangan kognitif siswa, (4) tokoh, penokohan, latar, plot dan tema yang menarik.

2) Validator Ahli Bahasa

Ahli bahasa yang menjadi validator pada penelitian ini adalah guru bahasa Jawa di SMP Kota Blitar dan guru kelas. Berdasarkan hasil validasi ahli bahasa diketahui bahwa persentase hasil validasi adalah 89,3\%. Dengan demikian, dapat disimpulkan bahwa buku Cergam Baja berada pada kategori layak dari segi bahasa. Bahasa yang digunakan untuk cerita harus mempertimbangkan penggunaan kosakata dan kalimat. Penggunaan bahasa mempertimbangkan perkembangan bahasa anak usia SD baik dari segi penguasaan struktur tata bahasa maupun dari segi kemampuan anak dalam memproduksi dan memahaminya sesuai dengan pernyataan [7]. 


\section{3) Validator Ahli Bahan Ajar}

Validator ahli bahan ajar pada penelitian ini adalah ahli dalam bidang desain bahan ajar. Persentase yang diperoleh dari hasil validasi ahli bahan ajar adalah $88,3 \%$. Berdasarkan hasil tersebut diketahui bahwa buku Cergam Baja termasuk dalam kategori layak. Buku Cergam Baja telah dikemas dalam tampilan dan desain yang sesuai dengan siswa dan guru. Dengan demikian hasil tersebut sesuai dengan pendapat [8] bahwa bahan ajar (modul) memiliki beberapa karakteristik, yaitu self instructional, self contained, stand alone, adaptive, dan user friendly Pertama, self instructional yaitu bahan ajar dapat membuat peserta didik mampu membelajarkan diri sendiri dengan modul yang dikembangkan. Kedua, self contained yaitu seluruh materi pelajaran dari satu unit kompetensi atau subkompetensi yang dipelajari terdapat di dalam satu bahan ajar secara utuh. Ketiga, stand alone (berdiri sendiri) yaitu bahan ajar yang dikembangkan tidak tergantung pada bahan ajar lain atau tidak harus digunakan bersama-sama dengan bahan ajar lain. Keempat, adaptive yaitu bahan ajar hendaknya memiliki daya adaptif yang tinggi terhadap perkembangan ilmu dan teknologi. Kelima, user friendly yaitu setiap instruksi dan paparan informasi yang tampil bersifat membantu dan bersahabat dengan pemakainya, termasuk kemudahan pemakai dalam merespon, mengakses sesuai dengan keinginan.

\subsection{Uji Keterbacaan}

Uji coba dilakukan dengan cara siswa dan guru diminta untuk mengisi angket keterbacaan siswa yang berisi tentang tampilan buku dan isi buku. Sedangkan untuk angket guru berisi tentang tampilan buku dan isi buku. Hasil dari angket keterbacaan siswa dan guru terdapat pada tabel 3 dan 4 sebagai berikut.

\begin{tabular}{llllllc}
\multicolumn{6}{c}{ Tabel 3. Hasil Uji Keterbacaan Siswa } \\
\hline Nomor & \multicolumn{2}{c}{ Siswa } & & & \multicolumn{2}{c}{ Jumlah } \\
Soal & $\mathbf{1}$ & $\mathbf{2}$ & $\mathbf{3}$ & $\mathbf{4}$ & $\mathbf{5}$ & 5 \\
\hline $\mathbf{1}$ & 1 & 1 & 1 & 1 & 1 & 5 \\
$\mathbf{2}$ & 1 & 1 & 1 & 1 & 1 & 5 \\
$\mathbf{3}$ & 1 & 1 & 1 & 1 & 1 & 3 \\
$\mathbf{4}$ & 0 & 1 & 0 & 1 & 1 & 5 \\
$\mathbf{5}$ & 1 & 1 & 1 & 1 & 1 & 5 \\
$\mathbf{6}$ & 1 & 1 & 1 & 1 & 1 & 5 \\
$\mathbf{7}$ & 1 & 1 & 1 & 1 & 1 & 5 \\
$\mathbf{8}$ & 1 & 1 & 1 & 1 & 1 & 5 \\
$\mathbf{9}$ & 1 & 1 & 1 & 1 & 1 & 5 \\
$\mathbf{1 0}$ & 1 & 1 & 1 & 1 & 1 & 48 \\
Jumlah & & & & & & 50 \\
Skor Maksimal & & & & & \\
Persentase & & & & &
\end{tabular}

Berdasarkan Tabel 3 diketahui bahwa skor angket keterbacaan siswa adalah 48 dengan nilai persentase sebesar 96\% dikategorikan "sangat layak". Nilai persentase tersebut termasuk dalam kategori rentang 90\%-100\% karena isi, bahasa maupun layout sudah sesuai dengan siswa.

Tabel 4. Hasil Uji Keterbacaan Guru

\begin{tabular}{|c|c|c|c|c|c|c|}
\hline \multirow{2}{*}{$\begin{array}{l}\text { Nomor } \\
\text { Soal }\end{array}$} & \multicolumn{5}{|c|}{ Guru } & \multirow{2}{*}{ Jumlah } \\
\hline & 1 & 2 & 3 & 4 & 5 & \\
\hline 1 & 5 & 5 & 5 & 5 & 5 & 25 \\
\hline 2 & 5 & 4 & 4 & 5 & 5 & 23 \\
\hline 3 & 5 & 5 & 5 & 5 & 4 & 24 \\
\hline 4 & 4 & 4 & 5 & 5 & 5 & 23 \\
\hline 5 & 4 & 4 & 4 & 5 & 5 & 22 \\
\hline 6 & 5 & 5 & 5 & 4 & 5 & 24 \\
\hline 7 & 5 & 5 & 5 & 5 & 5 & 25 \\
\hline 8 & 5 & 5 & 5 & 5 & 5 & 25 \\
\hline 9 & 4 & 5 & 5 & 5 & 5 & 24 \\
\hline \multicolumn{6}{|c|}{ Jumlah } & 215 \\
\hline \multicolumn{6}{|c|}{ Skor Maksimal } & 225 \\
\hline \multicolumn{6}{|c|}{ Persentase } & $95,5 \%$ \\
\hline
\end{tabular}

Berdasarkan Tabel 4 diketahui bahwa skor angket keterbacaan guru adalah 225 dengan nilai persentase sebesar 95,5\% dikategorikan "sangat layak". Sehingga dapat disimpulkan bahwa guru memberikan respon yang positif terhadap isi dan bentuk fisik buku Cergam Baja. 


\subsection{Revisi Produk}

Selama proses validasi, terdapat catatan revisi dari validator yang harus diperbaiki untuk mencapai kelayakan. Catatan revisi dari ahli cerita menyarankan (1) dalam cerita mengurangi petuah dari orang yang lebih dewasa, terutama di cerita keempat, (2) mengganti beberapa kata yang masih kurang baik untuk diucapkan dan (3) judul perlu dibuat lebih menarik, bukan menunjukkan pesan moral secara terbuka. Hasil revisi judul dapat dilihat pada gambar 3 .

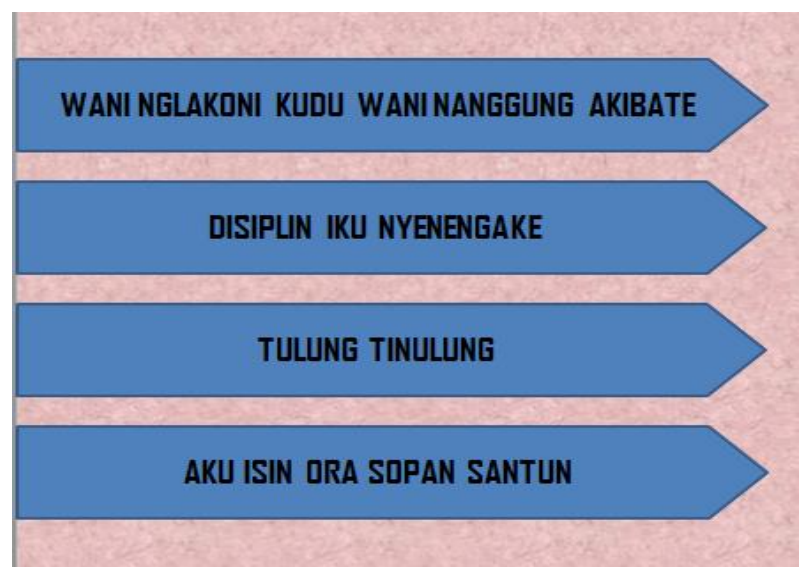

Gambar 2. Sebelum Revisi

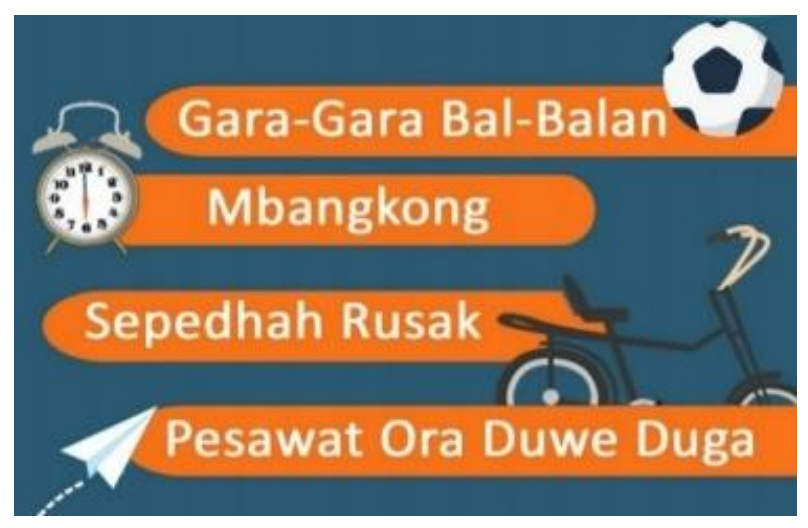

Gambar 3. Judul Percerita yang Direvisi

Catatan revisi dari ahli bahasa memberikan catatan revisi berupa ada beberapa ejaan yang perlu diganti agar sesuai dengan pakem bahasa Jawa yang benar. ejaan tersebut kurang sesuai dengan bahasa yang akan diajak berbicara sehingga harus diganti agar siswa juga belajar dari dini jika berbicara dengan teman dan orang yang lebih dewasa itu berbeda.

Catatan revisi dari ahli bahan ajar memberikan catatan revisi berupa (1) cover revisi agar lebih menarik perhatian siswa dan judul diganti "Juna lan Sabendinane", (2) bentuk soal cerita 1-4 dibuat lebih bervariatif, (3) konsistensi jenis huruf dan ukuran huruf supaya lebih mudah dibaca oleh siswa, (4) background untuk soal cerita diganti warna putih saja, dan (5) sertakan desain sampul belakang. Untuk desain cover sudah ada perbaikan, berikut adalah revisi dari desain cover tersebut. 


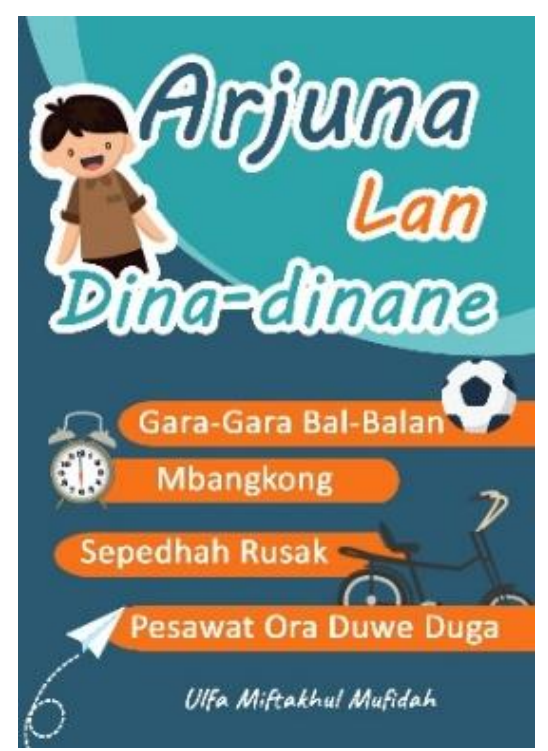

Gambar 4. Sebelum Revisi

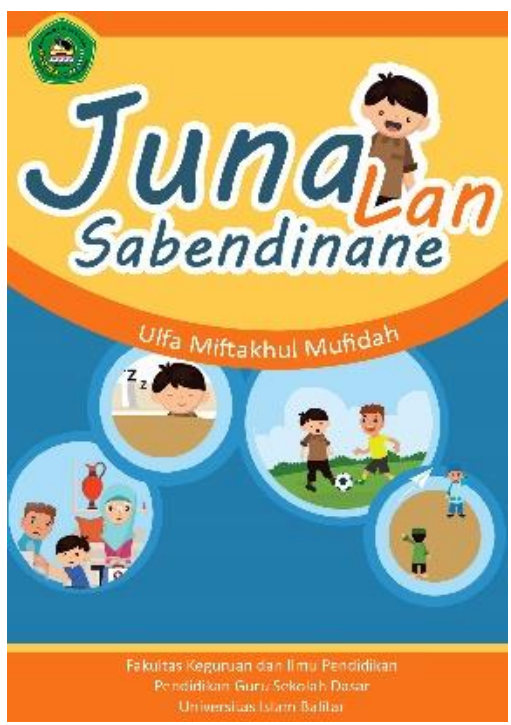

Gambar 5. Cover yang Direvisi

\section{KESIMPULAN}

Buku Cergam Baja yang dihasilkan telah melalui beberapa perbaikan dan sudah direvisi sesuai dengan saran dari validator. Materi yang disajikan dalam buku ini adalah materi cerita berbahasa Jawa. Cerita yang disajikan dalam buku Cergam Baja adalah cerita yang dibuat oleh peneliti sendiri. Buku Cergam Baja ini berisikan 5 cerita bergambar dan setiap cerita memuat Pendidikan karakter.

Buku Cergam Baja ini telah divalidasi oleh 10 validator yaitu 4 ahli cerita, 3 ahli bahasa dan 3 ahli bahan ajar. Buku ini juga telah diujicobakan kepada siswa kelas IV dan guru kelas. Persentase hasil dari validasi adalah $86 \%$ untuk ahli cerita, $89,3 \%$ untuk ahli bahasa, dan $88,3 \%$ untuk ahli bahan ajar. Sedangkan hasil dari uji coba adalah $96 \%$ untuk uji keterbacaan terhadap siswa dan 95,5\% untuk uji keterbacaan terhadap guru. Berdasarkan hasil secara keseluruhan dapat disimpulkan bahwa buku Cergam Baja layak untuk digunakan sebagai bahan ajar.

Buku Cergam Baja diharapkan menjadi sumber bagi siswa dan guru dalam memberikan materi pendidikan karakter pada siswa. Peneliti selanjutnya diharapkan mampu mengembangkan produk serupa dengan tampilan yang lebih menarik dan cerita yang disajikan juga lebih menarik lagi. 


\section{DAFTAR PUSTAKA}

[1] Arafik, "Pembelajaran Bahasa Jawa di Sekolah Dasar Berbasis Karakter", Malang: Fakultas Ilmu Pendidikan Universitas Negeri Malang, 2013.

[2] M. Deddy, "Metode Penelitian Komunikasi”, Bandung: PT. Rosdakarya, 2008.

[3] A. Zainal, "Penilitian Tindakan Kelas", Bandung: Yrama Widya, 2009.

[4] Z. Nur, "Pengembangan Buku Cerita Bergambar Bahasa Jawa untuk Meningkatkan Keterampilan Menulis dan Berbicara Siswa Kelas II MI Sabilul Huda Senden Peterongan Jombang”, Malang: Universitas Islam Negeri Maulana Ibrahim, 2008.

[5] F. Lukitosari Septiana, "Pengembangan Buku Cerita sebagai Upaya Peningkatan Penguasaan Kosakata Jawa Siswa Sekolah Dasar di Kabupaten Semarang”, Semarang: Universitas Negeri Semarang, 2016.

[6] D. Nufus Dinina, "Pengembangan Buku Pengayaan Cerita Anak Berbahasa Jawa Berbasis Pendidikan Karakter dalam Lingkungan Keluarga", Semarang: Universitas Negeri Semarang, 2013.

[7] R. Novi, "Pendidikan Bahasa dan Sastra Indonesia di Kelas Tinggi”, Bandung: UPI Press, 2007.

[8] Widodo, C.S. \& Jasmadi, "Panduan menyusun bahan ajar berbasis kompetensi", Jakarta: PT Elex Media Komputindo, 2008. 